\section{LA NOCIÓN DE VOCACIÓN: LLAMADA UNIVERSAL DE DIOS, RELATO DEL HOMBRE •}

Autor: Christophe Boureaux. O.P. Dominico. Profesor en el Centro de Estudios institucionales del convento dominico de Lille y en el Instituto católico de dicha ciudad.
Tras una precisión de vocabulario sobre los conceptos vocación, elección, predestinacion y sus diferencias en el mundo contemporáneo y en la Biblia, se detiene en precisar quién es el elegido y los peligroso de sentirse "único" por la elección. A continuación nos recuerda la vocación universal. Introduce el símil "vocación creación", invita a desterrar el subjetivismo de la misma, ya que la vocación cristiana del hombre es una manera de situar su existencia bajo la mirada de Dios.

DOI: https://doi.org/10.52039/seminarios.v46i158.1002

Antonio decía que nada de lo que había en el mundo lo ponía por delante del amor a Cristo. En sus conversaciones, hacía memoria de los bienes futuros y del amor de Dios por los hombres, él que no habia perdonado a su propio hijo, sino que lo había entregado por todos nosotros. Así persuadió a muchos para que abrazaran la vida solitaria. De esta manera $y$ desde entonces, también en las montañas, se erigieron ermitas y el desierto se transforma en una ciudad de monjes que, habiendo despreciado sus bienes, intentaban reproducir la vida de la ciudad celeste.

San Atanasio. Vida de San Antonio, 14,6-7

¡Sonido de campanas, canción de campanas, supra urbem, sobre la ciudad entera, con el aire desbordando resonancias! ¿quién toca las campanas? Nadie -sino el Genio de la Narración, mientras que cuenta cómo ya tres

- Por concesión de La Vie spirituelle, 729 (98) pp.641-661. Traducido del original francés por Alonso Morata. 
días antes de la entrada del Elegido las campanas se sorprenden moviéndose solas y no se detendrán hasta su coronación en la basilica de San Pedro.

Thomas Mann, El Elegido.

\section{Elección, predestinación, vocación: algunas precisiones de vocabulario}

“¿Dios mío, haz que yo no tenga vocación!" Así rezaba una joven de una católica familia de agricultores que, en el silencio de su habitación, oraba pidiendo que mejor que a ella el Señor eligiese a uno de sus cinco hermanos o hermanas más pequeños, para que siguiera la estela de su tío o su tía, abrazando la vida religiosa, tradicional en esa familia. Pero no sucedió como ella pedía. Ya que, unos años más tarde, ella seguía la tradición familiar, ingresando en una congregación de reciente fundación.

En nuestra cultura, la noción cristiana de vocación ha llegado a ser tan difícil de comprender como la de elección o predestinación. Las tres nociones son casi sinónimas en la terminología bíblica, aunque tienen sentidos diferentes en el lenguaje contemporáneo.

A finales del siglo XX en el mundo occidental, elección consiste

Elección en razón de aptitudes para asumir tareas en designar a uno para un cargo o una función y ésta se hace mediante escrutinio. Es la asamblea de votantes la que es sujeto de elección. Ser elegido, no es tanto haber sido escogido por algunos, cuanto enviado a un puesto para el que se necesitan ciertas aptitudes. La elección entraña una competencia ya verificada por los votantes. Ésta es frecuentemente el resultado de una campaña de promoción de un individuo que, sobre la base de un saber, de un saber hacer y de un comportamiento, se encuentra preparado para asumir nuevas tareas. La elección es la consecuencia de unos actos ya realizados en orden a otros que están por realizar. No es algo gratuito o inexplicable, sino que se justifica (la elección) por una cualificación anteriormente adquirida. El hecho de que se hable más frecuentemente de elecciones que de elección en general, muestra que se trata de un proceso habitual que nada tiene de misterioso. Las elecciones marcan profundamente hoy día la conciencia de las sociedades occidentales, en el sentido de una libertad adquirida como un bien del todo inalienable.

Esta mentalidad se encuentra muy alejada del sentido bíblico de elección, en la Biblia los elegidos son designados por la libertad inson- 
dable de Dios, cualesquiera que sean sus méritos. Es notorio, por ejemplo, que la incorporación de Matías a los once apóstoles en el lugar de Judas (Act 1,15-26), episodio que presentaría aparentes analogías con los procedimientos actuales de designación de alguien para una función o asociación o sociedad, se hace echándolo a suertes. Es Dios quien, respondiendo a la oración del grupo, elige y no los Once: "Tú, Señor, que conoces los corazones de todos, muéstranos, cuál de los dos (José llamado Barsabas, por sobrenombre Justo, y Matías) es el que tú has elegido...". Es preciso también explicar que la elección se hace, no según el criterio mencionado en el versículo 21 de ser "entre los hombres que nos han acompañado durante todo el tiempo en el que el Señor Jesús ha caminado a la cabeza de nuestro grupo... [para que] sea con nosotros testigo de su resurrección", sino según el conocimiento que Dios tiene del corazón de los candidatos. No es porque Matías haya acompañado durante más o menos tiempo a los Once con Jesús, por lo que es elegido por Dios. No es por su competencia apostólica por lo que los Once le agregan a su grupo, es por la elección divina. La elección bíblica está fundamentada sobre la fe en Dios, no en las obras Se elige según el conocimiento que Dios tiene del corazón del candidato de los hombres.

También la noción de predestinación está sometida, en nuestra cultura, a una revisión de sentido con relación a su raíz bíblica. Carga hoy día con una interpretación negativa que la asocia a un destino ciego. Significa en el lenguaje común que una determinación implacable se abate sobre la persona y aliena su libertad. Sin motivo, se atribuye a la teología de Calvino esta idea de que unos estarían predestinados al bien y la felicidad y otros a la perdición.

La existencia de predestinados al bien y predestinados al mal es un signo más entre otros tantos de que existe una voluntad exterior a la propia que dirige inconscientemente las elecciones de cada uno. Este no es el pensamiento de Calvino que, muy al contrario, se preocupa por preservar el misterio de la libertad de Dios que escapa a nuestra razón. Dios nos deja en libertad para elegir el bien y rechazar el mal fiándonos de su Palabra. Para Calvino nadie está predestinado al mal, la causa del mal se encuentra no en los designios de Dios, sino en las propias faltas del pecador. Nuestra razón, dice Calvino, es incapaz de penetrar en el designio de Dios, no tiene otro poder que el de aplicarse al mundo presente para manifestar allí la salvación de Dios. Nuestra razón acaba -la

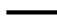


facultad de nuestro espíritu-, debe servir al mundo presente, ella sabrá sernos útil para llegar a Dios o para justificarnos a nosotros mismos por nuestros méritos delante de Dios. "Esaú y Jacob, escribe Calvino, hermanos engendrados de los mismos padres, de un mismo vientre [...] Todo es parecido en uno y otro, sin embargo el Juicio de Dios los dis-

Dios elige libremente para un destino peculiar tingue; porque elige a uno y rechaza al otro [...] Jacob es por tanto elegido, Esaú rechazado, y la distinción les viene por la elección de Dios, en cuanto que ellos no se diferenciasen nada en méritos" . Calvino, muy próximo al pensamiento bíblico, retoma a su manera la pregunta de San Pablo: “¿Qué diremos, pues? ¿Que Dios actúa injustamente? ¡De ninguna manera! Dios mismo dice a Moisés: 'Tendré misericordia de quien quiera y me apiadaré de quien me plazca'. Esto no depende, pues, de la voluntad ni del esfuerzo del hombre, sino de la misericordia de Dios" (Rom 9,14-16). La libre elección de Dios es una preferencia otorgada a algunos en vistas a un destino peculiar.

Es esto lo que choca con la conciencia contemporánea, alejada del pensamiento bíblico y habituada a rendir cuentas tanto del bien como del mal, es, en conclusión, la idea de una voluntad divina impenetrable para el pensamiento humano. El bien como el mal moral son para él méritos en el contexto de una justicia inmanente. La predestinación que resulta de una elección divina es un escándalo para el pensamiento que no encuentra el sentido de su existencia más que en él mismo o en su propio mundo. Calvino, al contrario, mostrando que la elección es obra exclusiva de Dios, quiere liberar al creyente de toda servidumbre intramundana. El creyente descubre que es salvado por Dios gratuitamente, independientemente de cualquier mérito, de cualquier acción buena, y que el sentido de la existencia le viene no del mundo presente sino de la misericordia de Dios. "Para Calvino la certeza de la elección se encuentra en Cristo. El catecismo de 1537 enseñaba: Cristo es aquel en quien se nos presenta la prenda de nuestra elección si nosotros lo recibimos y abrazamos por la fe [...] Poseyendo a Cristo por la fe paralelamente poseemos en él la vida. Esta experiencia en la que el designio eterno de Dios se manifiesta a nosotros en la vocación, se llama con-

1 CALVINO, J., Institución De la religión cristiana, 1541, III, 67-68. Citado por L. Schümmer, "Predestinación y destino en la síntesis de Calvino. La vida tiene un sentido" en A. Gesché (dir.) Destino, predestinación, destinado, París, Ed. du Cerf, 1995, pág. 113. 
versión, es decir el dominio de Dios sobre nuestra existencia"2. Dios predestina en la medida en la que él es el fundamento de la existencia, le da su cohesión y su sentido. La predestinación o la elección, en el lenguaje de Calvino, es así una manera de denominar la originalidad fundamental de cada vida humana, su seguridad. Esta singularidad es la fuente de su sentido, porque le permite escapar al caos de lo informe, lo no diferenciado, del poder del diablo que siembra la confusión. Ser predestinado, es ser elegido, puesto a parte, separado para ser conocido mejor y amado según un designio original. La predestinación bien entendida conduce así a la vocación general de todo creyente a celebrar la gloria de Dios en todos los actos de su vida, en todas las vocaciones a las que el creyente consagra su existencia.

Hemos llegado así a la noción de vocación específica. La pregunta del creyente es ahora la siguiente: ¿Tiene Dios un plan para mí? ¿Quiere Dios que yo oriente mi existencia de una manera específica? ¿Ha promulgado él un decreto por el que decide que yo deba casarme o entrar en la vida religiosa, aceptar un puesto determinado o prepararme en tal materia? ¿Cómo saberlo y a consecuentemente coincidir con el designio de Dios?

El término vocación en el lenguaje corriente no teológico, designa una especie de atracción irresistible más o menos razonada. Es una poderosa motivación interior que se expresa en forma de tareas y de funciones. "Tener vocación para" llega a ser así sinónimo de cualificación (estar cualificado para). Personas, lugares y cosas pueden tener "vocación para". En este sentido se dice que uno tiene vocación de jefe, o una ciudad vocación (atractivo) turística, etc. Contrariamente a la etimología latina (vocatio, vocare, llamar) y a su acepción bíblica, la vocación como tal no es el resultado de una llamada personal, sino sobre todo de una cualidad adquirida o innata para llevar a cabo algo. "Tener vocación para" es tener una aptitud cualificada. Se podría casi sustituir vacación (diligencia) por vocación para encontrar su sentido, en la medida en que "tener vocación" supone estar disponible para una obra entregándose con constancia, determinación y aplicación.

La pregunta: ¿Tiene Dios un plan para mi?

"Tener vocación para" = "tener aptitud para"

2 SCHÜMMER, L. o.c., pág. 128 (ver nota precedente). 


\section{¿Quién es el elegido?}

A partir de esta breve aclaración de los tres términos: elección, Vocación = cación en la lengua corriente y el que le es propio en el lenguaje teolódestino creyente fundamentado en una relacion personal con Dios gico. Tanto es así que el primero supone su aplicación a tareas concretas, mientras que el segundo, heredero de la semántica bíblica, los une en la significación común de un destino creyente fundamentado en una relación personal con Dios. El lenguaje corriente acostumbra a entender la elección, la predestinación y la vocación como consecuencias de actos humanos anteriores, en tanto que el lenguaje bíblico se sirve de ellos para designar la iniciativa de Dios sobre el hombre. En la lengua corriente, cualquiera es elegido, o tiene vocación para cualquier cosa, por el mero hecho de existir. En el lenguaje bíblico es lo contrario, él es lo que es porque ha sido elegido por Dios o porque ha recibido de Dios vocación para algo. No obstante, el lenguaje bíblico y el teológico no están libres de acepciones profanas. Y no es extraño que se den ambigüedades cuando se habla de vocación cristiana, religiosa o sacerdotal. Todos los discursos sobre las vocaciones eclesiales adolecen hoy día de un corrimiento semántico desde el sentido bíblico al profano.

Con la Escritura en la mano se puede decir que todo ser humano tiene vocación a la santidad, es decir a llegar a constituir la humanidad querida por Dios a su imagen y semejanza y así formar su pueblo, porque "Dios nos ha elegido en Cristo antes de la creación del mundo para que fuésemos santos e irreprochables ante Él, en el amor, Él nos ha destinado por decisión gratuita de su voluntad a ser adoptados como hijos suyos por medio de Jesucristo, para que la gracia que derramó sobre nosotros por medio de su Hijo querido, se convierta en himno de alabanza a su gloria" (Ef 1,4-6). Es evidente que toda vocación cristiana encuentra en estas palabras de la carta a los Efesios su raíz y su motor. Todo ser humano que elige a Dios, se dice que siente en sí esta moción íntima que le impulsa a ser el servidor del evangelio cerca de sus hermanos, encuentra en los términos elección, predestinación y vocación los calificativos adecuados a su orientación de vida. En tanto que el paso desde esta significación general a una raíz concreta no se puede hacer más que como préstamo de significados profanos que la cultura ambiente pone a su disposición. Este deslizamiento semántico debe ser 
controlado si no queremos que se convierta en un fuerte patinazo. Es todo el problema de la articulación entre disposición subjetiva y verificación objetiva eclesial de la vocación que M. Sauvage ${ }^{3}$ describe brillantemente en su gran artículo "Vocación". M. Sauvage subraya así el papel fundamental del que acompaña una vocación. Éste debe permitir el impulso generoso hacia la santidad, que es el motor de toda vocación, encontrar su "pista de aterrizaje" en un servicio concreto en la Iglesia.

El acompañante ayuda a la persona a reconocer en los signos de su vida cuáles son llamada del Espíritu; y por esa razón lo acompaña en la relectura de su historia, la purificación de sus motivaciones, así como en la adquisición de las costumbres concretas que exige una vida según el Espíritu en el transcurrir de cada día [...] El Espíritu no puede brotar (surgir) más que en la aceptación realista de la verdad de las personas y sus situaciones ${ }^{4}$.

Esto significa que no se podría enfocar cristianamente la vocación en la Iglesia ni como elección para un puesto, ni como predestinación a un estado particular, ni como una cualificación divina para unas tareas determinadas de enseñanza o de gobierno. M. Sauvage escribe así con acierto:

La declaración de la llamada manifiesta a la Iglesia que ella misma es llamada en sí, que no existe más que porque hay Otro que llama. Ninguna comunidad, ninguna congregación tiene su origen en ella misma, y la Iglesia nace y renace constantemente gracias la adhesión libre de personas que están en una relación transcendente con el Dios vivo. Es evidente que esta realidad de una acción libre, de una Palabra creativa, de una intervención transcendente de Dios aparece tanto más pura cuanto que el hombre que se declara no ha sido obligado a hacerlo por presiones insidiosas o explícitas, contrarias a la autenticidad de la vocación divina y del sacramento de la llamada eclesial. Sólo Dios es el que da crecimiento a su pueblo (hace crecer a su pueblo). La llegada de vocaciones inesperadas manifiesta en primer lugar la gratuidad de Dios que llama "a quienes quiere". Cada vocación que se manifiesta invita a la Iglesia a reconocerse como asamblea de personas libres y liberadas [...]. No se trata de buscar consolidar las instituciones,

3 SAUVAGE, M, Artículo: "Vocación" Diccionario de espiritualidad, Beauchesne, 1993, col 1092-1158.

4 Ibidem, col 1139.

Toda llamada tiene origen en la iniciativa de Otro que llama 
sino de estar atento a las personas, de ayudarlas a reconocer eventualmente en su propio corazón una palabra de Dios que les llama5.

Este recuerdo de puro sentido común puede resonar como una profecía audaz en un tiempo en el que las vocaciones son escasas. En este momento en el que el número de candidatos al ministerio presbiteral y a la vida consagrada se encuentra en Francia* en un nivel drásticamente bajo, las palabras de M. Sauvage invitan a una clara lucidez sobre la noción de vocación cristiana. Porque está claro que el riesgo de ver reaparecer los viejos demonios del catolicismo es en ese caso muy grande. Cuanto más se debilita un cuerpo, más vulnerable se hace. Estos viejos demonios tienen por nombre intransigencia doctrinal, superyo sacerdotal, ritualismo cultual, funcionarismo eclesiástico, autoritarismo legalista, menosprecio hipócrita (solapado). Esos son todos los defectos del elegido cuando se contempla a sí mismo. Se parece al hijo único de buena familia, que es tanto más odiado cuanto más dotado. Heredero de Peligro de la reputación de sus antepasados y de una gran riqueza, se cree el cen-

sentirse "elegido", situado aparte, con identidad radicalizada tro del mundo, tiene una opinión incontestable sobre todos los temas, interviene a tiempo y a destiempo. En el momento en el que dejen de ocuparse exclusivamente de él, se creerá rechazado y perseguido, acusará a los otros de no respetarlo. Piensa que su arrogancia es signo de su superioridad y considera que cada una de sus palabras o de sus acciones está al servicio del patrimonio de valores que él encarna. Es fácil para el elegido creer que tiene una vocación que le sitúa aparte, le distingue de la masa de los otros hombres, porque los miembros de su fraternidad, de su grupo o de su comunidad religiosa proyectan sobre él todas las esperanzas de ver perpetuarse en su persona lo que son y representan ellos mismos. Esta psicología colectiva de minoría social favorece la emergencia de cierto tipo de vocación. Pero estas vocaciones en espejo conducen al candidato a peligrosas aporías: portadores de los intereses de un grupo restringido pierden el contacto con la realidad y se cierran en el marco estrecho de la autorreproducción de grupo. Son alienantes para el candidato que no puede más que asirse y refugiarse en la identidad recibida. Se reconocen necesariamente por una identi-

\footnotetext{
5 Ibidem, col 1135.

* Así como en toda Europa, salvo en unas pocas diócesis.
} 
dad radicalizada. Porque para el elegido cambiar, es abandonar la identidad exterior que se le ha impuesto, y perder su identidad es morir. De esta forma el elegido se reconoce en este eslogan: "Antes morir que cambiar". Porque la muerte " muerte" es más soportable que la muerte "viviente". Prefiere morir con la conciencia de preservar su identidad, antes que continuar viviendo y perdiendo la identidad que le ha sido impuesta y con la que él se ha desposado.

\section{La vocación universal a la santidad, a la fraternidad}

Esta última observación obliga en consecuencia a un severo correctivo de la idea cristiana de vocación. En efecto, como enseña la constitución Gaudium et spes del concilio Vaticano II, la llamada fundamental que Dios realiza a los hombres es una vocación universal a la fraternidad. Dios llama no para poner aparte a una fracción de la humanidad, sino para que toda la humanidad llegue a ser santa como él mismo es santo:

Proclamando la más noble vocación del hombre y afirmando que un germen divino ha sido depositado en él, este santo Sínodo ofrece al género humano la colaboración sincera de la Iglesia para la instauración de una fraternidad universal que responde a esta vocación. Ninguna ambición terrestre empuja a la Iglesia; ella no vislumbra más que una sola meta: continuar, bajo el impulso del Espíritu consolador, la obra misma de Cristo, que vino al mundo para dar testimonio de la verdad, para salvar, no para condenar, para servir, no para ser servido 6 .

Afirmando que Dios es el principio y el fin de todos los hombres, la noción cristiana de vocación no conlleva idea de separación sino de comunión. La llamada de Dios dirigida a los hombres no es una llamada separadora, sino unificadora, porque "Dios quiere la salvación de todos los seres humanos" (1 Tim 2,4). No es la llamada de Dios la que separa a los hombres, unos de otros, es la respuesta de unos y la no-respuesta de otros a su llamada la que los separa entre ellos. En un marco más preciso, pero con la misma lógica, el concilio Vaticano II

Dios llama paraque toda la comunidad sea santa

Separa la respuesta de unos y la no-respuesta de otros

6 Gaudium et spes, $3 \S 2$. 
hace experimentar una inflexión idéntica cuando se expresa a propósito de la llamada de Dios a la santidad en el capítulo V de Lumen gentium. Dios hace a los santos (aquellos que están en el calendario) pero él llama a todos los discípulos de Cristo a la santidad cualquiera que sea su estado de vida: "Es por lo tanto evidente para todos que la llamada a la plenitud de la vida cristiana y a la perfección de la caridad se dirige a todos los que creen en Cristo, cualquiera que sea su estado o su rango: en la sociedad terrestre esta misma santidad contribuye a promover más humanidad en las condiciones de existencia"7. Dios da a todos una vocación a la santidad que se manifestará en los diferentes estados de vida "según sus propios dones y recursos, por el camino de una fe viva que estimula la esperanza y se actualiza por la caridad"8. Frente a la antropología moderna que concibe al hombre bajo el aspecto de individuo aislado antes que como cuerpo colectivo, el concilio retoma la concepción bíblica en la que Dios, por el mismo hecho de ser

Dios se dirige al hombre para hacer un pueblo de hermanos comunión trinitaria, se dirige a su confidente humano en su identidad colectiva para hacer de ellos un pueblo de hermanos. Cada ser humano tiene una vocación divina porque pertenece a la multitud salvada en Cristo: "Porque a los que conoció de antemano, los predestinó también desde el principio a reproducir la imagen de su Hijo, llamado a ser el primogénito entre muchos hermanos. $\mathrm{Y}$ a los que desde el principio predestinó, también los llamó; a los que llamó, los puso en camino de salvación; y a quienes puso en camino de salvación, les comunicó su gloria" (Rom 8,29-30).

Del pensamiento del Concilio Vaticano II se deduce que la noción de vocación debe entenderse de dos maneras distintas según se refiera a Dios o al hombre. La vocación entendida como el hecho por el que Dios llama, elige o predestina, es universal, en ella no hay acepción de personas, Dios revelándose ofrece a todos el poder llegar a ser hermanos, del mismo modo que habiendo manifestado su santidad en el Hijo, la ofrece a todos sus discípulos. La idea de vocación aplicada a la acción de Dios se condensa en el mandamiento de Jesús con el que cierra el pasaje sobre el amor a los enemigos: "Sed perfectos como vuestro Padre celestial es perfecto" (Mt 5,48). Perfecto es aquí la traduc-

\footnotetext{
7 Lumen gentium, 40.

8 Ibid, 41 .
} 
ción del griego teleioi que significa ser completado o acabado, haber llegado a la meta, no carecer de nada. Esta misma idea de universalidad es desdibujada en el pasaje paralelo de Lucas que pone compasión. Los exégetas quieren ver allí una recuperación del mandato del Señor a Moisés en el Levítico $(19,2)$ : "Sed santos, porque yo soy santo, yo el Señor vuestro Dios."

Cuando el término vocación tiene a Dios por sujeto, tiene un sentido activo y universal. Dios se revela a la humanidad, o a una porción de la humanidad, y no a la suma de hombres individuales. Si se puede decir -ya veremos en qué sentido más adelante- que Dios se muestra a tal persona en particular, no es más que para hacerlo mensajero de su palabra destinada a todos. Es lanzarse a un debate sin salida el buscar particularizar la vocación que viene de Dios. Para el cristiano, en sentido estricto del término, la única vocación que viene de Dios es una vocación a la santidad, o sea la construcción total de su humanidad a imagen y semejanza de Dios. El hombre es llamado por Dios a ser perfecto, a encontrar la meta de su existencia en Dios, y todos los caminos son posibles con tal que adopten el que es propio de Cristo. Exigir a Dios que nos señale cuál es la vocación particular a la debemos tender en nuestra existencia es volver a caer, imitar la figura de Tomás, el incrédulo que, según el evangelio de Juan, pregunta: “¿Cómo podremos conocer el camino?" (Jn 14,5). Jesús responde que él es el camino y que el Padre enviará el Paráclito "que os enseñará todas las cosas" (Jn 14,26). Dios tiene esta sola vocación, la de llamar a la humanidad entera a responderle y a dejarse configurar a su imagen y semejanza para conseguir su perfección. Retomando el relato bíblico en su totalidad, asistimos, a reiteradas y variadas formas de llamada de Dios a que el hombre le responda. Porque Dios gusta de todas las formas de discurso, a excepción del monólogo, y como dice la tradición judía, Dios ha creado al hombre para que él le cuente historias. Así como Adán y Eva se esconden "al oír la voz del Señor que se pasea por el jardín" (Gn 3,8$)$ y responden con temor cuando interpela al hombre, preguntándole: “¿Dónde estás?” (Gn 3,9), otros personajes como Samuel (1 Sm 3,1-10) o san Pablo (Act 9,4) van aprendiendo progresivamente a responder a la llamada de Dios. Sería un contrasentido aislar las figuras bíblicas individuales y hacer de ellas el modelo de destinos particulares. Ellas son, por el contrario, el signo y la anticipación de la Jeru-

Dios se revela a la humanidad. No particulariza 
salén celeste donde hombres de toda tribu, lengua y nación, responderán "como la voz de una inmensa muchedumbre...a la voz que salía del trono" (Ap 19,5-6). Los ciento cuarenta y cuatro mil elegidos son el Vocación símbolo de la humanidad reconciliada entre ella y con Dios porque resde Dios, entablar diálogo con la humanidad ponde a la llamada universal de Dios. Para expresarlo en términos clásicos, la vocación de Dios es entablar el diálogo con la humanidad entera, por su Palabra y su Espíritu.

\section{La vocación es una creación}

Habiendo aclarado con lo dicho anteriormente el término vocación, cuando tiene a Dios por sujeto, nos queda ahora examinar cómo se aplica a la existencia del hombre. ¿Se puede decir que Dios predestina a cada hombre a una vocación singular? Nosotros responderemos con un sí y un no a esta pregunta. Sí Dios llama, predestina o elige a cada uno por su Espíritu infundido en toda creatura. No, Dios no llama, no predestina o elige a todo hombre a una vocación singular, a una

¿Tiene Dios un plan de existencia de antemano preparado para mi? tarea o una función específica en su pueblo o en la sociedad. La cuestión concreta es entonces: $\iota$ se puede aplicar a todo hombre el esquema de vocación que el relato bíblico emplea para las grandes figuras de elegidos como Samuel o san Pablo? Podemos de esta manera volver a la cuestión planteada más arriba: ¿tiene Dios un plan de existencia de antemano preparado para mí? ¿Dios me llama a una forma concreta de existencia?

Es preciso hacer constar que este género de pregunta, que se encuentra aún con demasiada frecuencia inducida en una lamentable pastoral vocacional, está puesta en primera persona. Ella manifiesta un centrarse el sujeto sobre sí mismo y corresponde a una búsqueda de identidad. Esta búsqueda es saludable en la medida en la que se efectúe en la presencia de Dios, pero tiene el riesgo de acabar siendo patológica, si no se ve acompaña de un descentramiento que lleve a descubrir a Dios en el rostro de los más próximos. El primer paso a dar, en esta marcha de búsqueda de las vocaciones, es el de acordarse e intentar comprender que teniendo delante a Adán "el Señor dijo: 'No es bueno para el hombre estar solo"" (Gn 2,18). Esto significa, no que sea preciso rechazar el celibato, sino que el hombre no encuentra su cami- 
no más que en el trato social. Es insertándose en la sociedad, y más concretamente en un grupo determinado, como se forja la identidad personal. ¿Pero saber qué es cada uno, es la vocación cristiana? En este punto también nos permitimos responder sí y no. Sí, en la medida en la que se elija a Dios como compañero de vida. No, porque esta cuestión filosófica fundamental no tiene necesidad de la revelación cristiana para encontrar respuesta: Sócrates había escogido como lema propio la fórmula del templo de Apolo: "Conócete a ti mismo".

La vocación cristiana del hombre es una manera de situar su existencia bajo la mirada de Dios. Dios es creador. Él es Palabra que invita a un diálogo en una historia. Él es presencia íntima que impulsa a una permanente salida de sí. Es a partir de estos tres elementos como se hace posible entender la noción de vocación aplicada al hombre creyente. Nosotros podemos así responder a la siempre difícil cuestión de los responsables de las vocaciones en la Iglesia: ¿Cómo adaptar el sentimiento subjetivo de la vocación a las exigencias objetivas de la situación? ¿Cómo hacer que un joven maduro atraído por la vida evangélica transforme su sentimiento interior en deber de estado y llegue a ser vicario de una parroquia o una joven hermana hospedera en un monasterio?

La tentación de querer ocupar el lugar de Dios es grande. El Señor X es capellán de prisiones porque Dios lo ha querido. Es su vocación, Dios ha hablado por boca de la madre abadesa o del vicario general que hace los nombramientos. Es posible, pero no es seguro, y sobre todo es extremadamente peligroso para Dios.

Ahora bien, la vocación es como la creación del mundo o comienzo de todas las cosas (ver Is 43,7). La creación nos ha sido contada después de que ha pasado, pero criatura alguna estaba presente allí. En los relatos bíblicos, el $\mathrm{P}$. Gibert ${ }^{9}$ ha demostrado que los relatos de vocación tienen la misma estructura que los relatos de la creación. Describen un origen inesperado (novedoso), un acontecimiento que se oculta aunque es relatado en una historia. ¿Cuál es el origen de una vocación cristiana específica? Es clara la tentación de buscar una respuesta que relacione este origen con un hecho preciso: sucedió en tal periodo de mi vida, o tal día, o en tal hora o en tal lugar, etc. Pero hay otros elementos que apenas se citan y sería oportuno añadir como que hacía calor,

${ }^{9}$ GILBERT, Biblia, mitos y relatos del principio, Ed. du Seuil, París, 1986.

Dios es

Palabra que invita a un diálogo en una historia

La vocación es como la creación, inesperada

$$
\text { (1) }
$$


que acababa de encontrarme con tal persona, que había leído tal libro. Así el conjunto de factores determinantes no cesa de incrementarse, hasta tal punto de que, por sí mismo, ninguno es significativo, describiendo entre todos una constelación de causas. La vocación de cada uno es original como la creación: es el acontecimiento inaprehensible que permanece cuando se han agotado todas las tentativas para explicarlo. Reconocer por la fe que el mundo es una creación de Dios o descubrir en sí mismo la llamada de Dios señalándola como vocación es el fruto de una docta ignorancia, no la abdicación de una inteligencia fideísta por perezosa. Lo incognoscible o inabarcable aparece poco a poco a medida que las investigaciones se esfuerzan por responder: ¿por qué esto es más importante para mí que cualquier otra cosa? ¿cómo he llegado yo aquí? La vocación es, pues, como la creación, el lugar irreductible a las explicaciones que de ella se derivan. Es una ruptura instauradora en el continuum de las leyes del mundo. La vocación es la interpelación primera más allá de la cual no se puede uno remontar, pero desde la que solamente se puede descender, como el barco que no encuentra su esencia nada más que navegando por el río.

Así la vocación llega a hacerse inasible al tiempo de la historia.

Vocación inasible como la de Pablo en el camino de Damasco

El ejemplo más famoso de esa imposibilidad de encerrar la vocación en un relato único es el de la vocación de Pablo en el camino de Damasco. Tres relatos de hechura diferente en los Hechos (9,1-19; $22,4-21 ; 26,9-18)$ se añaden al de la carta a los Gálatas $(1,13-24)$ para dar cuenta de un acontecimiento inexplicable, fundante del destino de san Pablo. Estos relatos tienen, tal como los describe el P. Gibert ${ }^{10}$, cuatro características: 1 . Ponen en escena dos protagonistas de los cuales uno es humano y el otro sobrenatural. 2. El personaje sobrenatural toma la iniciativa y dirige el juego. 3. La tarea o mensaje transmitidos, parecen superar las posibilidades del personaje humano que pone como excusa su debilidad. 4. Todo es garantizado por un signo.

Según la lógica del relato, parece existir en el mismo un comienzo en la historia de esa vocación. Pero en realidad el punto cero de la vocación no cesa de ir hacia atrás en el mismo momento en el que se está en el punto de lograr todo su significado conservando su fuerza de interpelación. Un acontecimiento fundante no se deja representar como

10 Ibidem, pág. 215. 
un punto sobre una línea. "El origen, escribe P. Ricoeur, no pertenece a la memoria que sondea los pasados más hondos de la experiencia; en este sentido es inmemorial. ¿Cómo, desde entonces, unifica el origen desde el centro mismo de la experiencia histórica, sino reconociendo a posteriori la fuerza inaugural del origen en el que él continúa y perpetúa la energía inicial?"'11. Como el río sobre el que el barco navega, la fuente es inasible para el barco: no solamente porque el barco tiene demasiado calado como para navegar sobre el hilillo de agua que brota de la tierra, sino también porque el agua misma viene de las profundidades, de la lluvia, de las nubes, de la mar, etc. Así la fuente está tanto río abajo como río arriba del barco (por encima como por debajo del barco). Para san Pablo la fuente divina de su vocación es eterna, está tanto en el pasado polvo del camino como en su presente-futuro, con cuatro velocidades diferentes que originan relatos variados.

\section{La vocación como conclusión del relato}

Toda vocación específica no es más que el relato del conjunto parcial de los elementos que han contribuido a diseñarla en función de los destinatarios de ese relato. Una vocación específica es el intento de ordenar, en un relato significativo, todo lo que precede a la realidad en la que se encuentra el cristiano en el momento en el que trata de explicar que está bajo la mirada de Dios. Así la vocación se encuentra en el orden de la descripción y no en el de la prescripción. Nadie puede jamás prever el camino y la meta a la que llegará su existencia. La vocación es el resultado de un destino original, de un camino de vida, una vez que el camino está recorrido. Es por tanto esencial distinguir bien entre vocación de Dios y vocación del hombre ante Dios. La vocación de Dios es la oferta gratuita de fraternidad y santidad a la que es llamada a responder la humanidad entera. La vocación del hombre es el título del relato en el que él busca reunir los elementos que le vienen a la conciencia cuando se preocupa por conocerse a sí mismo ante Dios. Así no hay vocación que no se haya realizado. No hay, por ejemplo, vocación presbiteral, hasta que el obispo la ha reconocido en la lla-

11 RICOEUR, P., Pensar la Biblia, pensar la creación. París. Ed. du Seuil, 1998, pág, 81.

Vocación: resultado de un destino original, una vez está recorrido el camino 
mada de la ordenación. Pero el ordenando no tiene por ello una futura vocación episcopal. De la misma manera, la llamada subjetiva interior que sienta una catequista no será suficiente para definir que hay vocación presbiteral. Es la Iglesia como cuerpo colectivo, sacramento de comunión santa que viene de Dios, la que, en un momento determinado, ratifica la historia del candidato como relato de vocación, expresándolo mediante el acto institucional del obispo o del superior religioso. El reconocimiento de una vocación es el término provisional de un relato de vida. Quien dice relato, dice también oyente del relato. Una vocación específica no puede por consiguiente ser separada del grupo en el que este relato será recibido.

Se puede preguntar ahora ¿cómo se organiza este relato? o tam-

La Iglesia ratifica la historia del candidato como relato de vocación bién, ¿para qué sirven los relatos vocacionales que la Biblia nos ofrece? Aun así la comparación entre los relatos de la creación y los relatos vocacionales es esclarecedora. La teología bíblica ha adquirido definitivamente la idea de que los relatos de creación no son historias naturales. Cuando Dios crea en siete días la totalidad de los astros, de los planetas y de las bestias, no nos proporciona las claves de las ciencias paleontológicas. El (extremismo) creacionista que resulta de una lectura literal y fundamentalista de la Biblia es "una forma de suicidio del pensamiento. Coloca en la vida una falsa certeza, porque confunde inconscientemente las limitaciones humanas del mensaje bíblico con la sustancia divina de este mensaje"12. Esta es la cuestión: "¿Dios ha creado los zorros, los pollos y las estrellas de mar?" es esta pregunta más insignificante que esta otra: ¿Dios me ha hecho nacer para ser dominico, madre de familia o almirante?". La magnífica sillería de la catedral de Amiens nos ha dado de una vez por todas la clave de este género de pregunta. En este coro cerrado, alrededor del cual transcurre la vida de la ciudad platicando y negociando, la iconografía cuenta el gran relato bíblico en los entrepaños esculpidos, los apoyabrazos y las misericordias. Todas las criaturas de Dios y los personajes bíblicos representados revelan su vocación divina, cuando se actualiza en este principio del siglo XVI en el canto de la misericordia y de la gloria de Dios por los canónigos capitulares. $\mathrm{El}$ anacronismo de la escultura muestra a

12 Comisión bíblica pontificia, La interpretación de la Biblia en la Iglesia, París Ed. du Cerf, 1994, pág. 64. 
Abraham o María como un hombre y una mujer del siglo XVI con el carnero, el asno y el buey, los mercaderes burgueses, el soldado con armadura y cíngulo, dan una respuesta incuestionable a la pregunta: “¿Dios ha señalado a cada uno su vocación?" El relato de su existencia se superpone a la creación del mundo para desembocar así, hacia 1519-1522, expresando la santidad y la comunión de Dios mediante la vocación de los clérigos de Amiens. Todos quedan "entrelazados en esas historias", según la fórmula sugestiva de W. Schapp ${ }^{13}$. Su identidad presentada bajo la mirada de Dios, su vocación, es el resultado de historias en las que ellos son atrapados como en la red de Simón Pedro (Lc 5,1-11) recibiendo su vocación del mismo Jesús: "No temas, desde ahora te haré pescador de hombres. Y llevando las barcas a tierra, dejándolo todo lo siguieron." Nosotros que leemos este texto dos mil años más tarde, sabemos que la vocación de Pedro no es el programa de vida que él se había fijado aquel día. No es su verdadera vocación más que a través de nosotros que la leemos en el evangelio tras la reprimenda (Mc 8,33), después de la oración de Jesús para que la fe de Pedro no desaparezca (Lc 22,32), a continuación de la promesa de seguir a Jesús y de las negaciones (Mt 26,33 y 26,70 ó Jn 13,36 y $18,25)$ y después de que "otro ha ceñido su cintura" (Jn 21,18). Hoy día sólo nosotros somos contemporáneos de la vocación de Pedro, porque nosotros sabemos, por la fe, que realmente él fue la verdadera piedra sobre la que Cristo ha fundamentado su Iglesia (Mt 16,18).

Toda vocación humana ante Dios es como la de Pedro. Para ser conocida, necesita un relato que, como los relatos evangélicos, recoja y organice los acontecimientos de la existencia. Contar una vocación, es intentar acceder a esa constelación de intenciones que envuelven ese momento inescrutable en el que Dios llama a cada uno a ser santo como él es santo, a ser perfecto, universal como él mismo es perfecto y universal. Toda vocación singular es un relato, es decir un breve texto que, como un tejido (tejido y texto tienen la misma etimología: de tessere, tejer una pieza, enredar, de donde viene el sentido de la fórmula de Schapp, entrelazarse), anudar una multitud de intrigas narrativas. Así

Toda vocación humana necesita un relato que organice para ser conocida

13 SCHAPP, W., Entrelazamiento en las historias. El ser del hombre y de las cosas. París. Ed. du Cerf, 1992. 
tener vocación es dejar anudar el hilo de la propia historia a la de otras historias: la de una diócesis, una abadía, un instituto de vida consagrada, un cónyuge, etc. Por comodidad y porque no podemos actuar de otra manera, nosotros recortamos un trozo de ese tejido para contemplarlo. Pero los hilos del tejido son de hecho infinitos: se remontan a los orígenes y conducen hasta el fin del mundo. Como el velo de Verónica14, cada vocación es reconocida como tal por otros si pueden descubrir en él el rostro curiosamente pacífico de Cristo subiendo al Calvario. Cada una de las vocaciones particulares de los discípulos de Cristo será, finalmente, unificada en la túnica inconsútil de Cristo tejida de arriba abajo (de una sola pieza) (Jn 19,23).

\section{Tener vocación, es llamar a la escucha}

Dios llama a cada uno a responder de manera singular a su llamada universal. Diálogo

Vocación de Dios, vocación del hombre. La una no se entiende sin la otra. La primera es activa, manifiesta la libre iniciativa de Dios que sale de sí mismo para abrazar a todas sus criaturas con sus dos manos, el Hijo y el Espíritu según la metáfora de san Ireneo ${ }^{15}$. La segunda es pasiva (soportada). Nosotros padecemos nuestra historia antes de que sea asumida en un relato. Toda vocación nace en el seno de un entrelazamiento de historias bíblicas, eclesiales, familiares, sociales y políticas. La vocación de Dios es una llamada universal a la santidad y a la fraternidad, a la comunión. Se identifica con la multitud de elegidos, esto es con la humanidad, toda ella entera llamada a reconocer en Cristo al primer nacido entre una multitud de hermanos. La vocación de Dios es, pues, la palabra en la que puede surgir una vocación humana. Ésta es la respuesta a aquella. La vocación del hombre es el relato del diálogo entre Dios y una persona concreta. De esta manera Dios no llama a unos pocos a una vocación específica, sino que llama a cada uno a responder de manera singular (personal) a su llamada universal. En el primer caso, Dios se vería forzado a un monólogo; en el segundo, Dios provoca un diálogo.

\footnotetext{
14 Verónica muestra el velo al separarse de Cristo en $E l$ Cristo con la cruz a cuestas de Jerónimo de Bosch en el museo de Gante. No es Cristo que ve su propia imagen, somos nosotros que con esa imagen comprendemos su vocación mesiánica.

15 Ireneo de Lyón, Adversus haerexes, IV, Pr. 4.
} 
Cuando una persona dice: "yo creo que tengo vocación de consagrar mi vida a Dios", es necesario entender: "déjame que te hable de mi historia con Dios". En una sociedad culturalmente estable en la que las funciones son fácilmente reconocibles, la primera proposición podría cortocircuitar las mediaciones y llegar a ser: "yo creo que tengo vocación de ser sacerdote, hermana del Buen Pastor, zapatero o madre de familia." Pero este abuso de lenguaje cae por sí solo, cuando las identidades y los roles sociales evolucionan rápidamente, como es el caso de nuestras civilizaciones occidentales. La función identificativa de los relatos del sacerdote, hermana del Buen Pastor, profesionales o familiares en este caso tiende a diluirse y a perder su función de signo de la vocación de Dios. La función de devolución del signo a otra cosa que la hace desaparecer. El signo llega por sí mismo a su propio fin y la vocación del hombre se cierra en el propio monólogo. La vocación de la Iglesia habla de la Iglesia, la vocación del sacerdote habla del sacerdocio, la del profesional de su profesión, etc. Y su particularidad no responde en manera alguna a la vocación universal a la santidad. En tanto que la vocación particular del hombre debe ser un signo de la vocación de Dios, el uso del signo "vocación" deriva a un signo del sentido tener vocación en tal grupo, en tal familia. El uso prevalece sobre el signo que se devalúa.

Esto es lo que angustiaba a nuestra joven del principio: la costumbre pedía que en su familia creyente hubiese siempre algún clérigo ${ }^{16}$. Ahora bien, su auténtica oración era pedir ser capaz de poner su

16 P. Warnier en su libro La decisión, París, Nouvelle cité, 1990, presenta un buen ejemplo de relato entrelazado en historias de vocación. El libro cuenta cómo el autor es sacudido por la idea de una vocación de sacerdote inducida por su medio ambiente familiar como punto de partida de su edad adulta. "Unos meses después de esa peregrinación a Lourdes, en ausencia de Pedro, una tarde de junio llena de olores, en la "Habitación de los muchachos" en el pabellón Juigny, después de que su madre había venido a arroparle y le había dado un beso, súbitamente, como había ocurrido dos o tres años antes en la Theullerie, le preguntó de nuevo: "¿Sabes, Patricio, lo que serás en la vida?. Patricio, como murmurando y hablando entre dientes, con el tono ruboroso en su rostro, respondió en un confuso farfullo del que parecía deducirse que quizás tomase el camino del sacerdocio [...] Era como si surgiese de lo más profundo de sí mismo una revelación que jamás se le había presentado explícitamente. Una especie de sentimiento sin forma que yacía en el fondo de su deseo y de su voluntad. Tenía la sensación de que habían puesto en él este tema, banal, pero con una especie de complicidad y curiosidad acuciantes y un tanto indiscretas. Su madre casi le había violentado [...] Y después, una segunda pregunta de su madre, que debía haber sido tomada en confesión por el P. Decourt, agudiza su sentimiento de que había sido cogido en la trampa de la expresión de un deseo que, de pronto, se convertía en proyecto, con sus coacciones y sus atractivos, con los sacrificios que exigía y las seducciones que operaba" p. 80 . 
porvenir entre las manos de Dios y hacer de su vida un signo de Dios. Ella buscaba ejercer la función de signo porque era creyente y buena católica, pero no quería ser el signo en ${ }_{s}$ uso en su medio social. Toda vocación humana tiene la tendencia a cerrarse en ella misma y a terminar siendo una función, una costumbre. Toda sociedad, también la Iglesia, intenta por su propia naturaleza prevenirse contra el deterioro de los tiempos, definiendo los roles que mejor sirven para su finalidad a través de instituciones estables. Postula implícitamente que, estando asentada de una vez por todas, ella debe proporcionar historias particulares en su propia historia. Entiende que lo bien fundamentado de su misión ha asegurado definitivamente el significado de los signos que utiliza. Todo signo lleva en sí de esta manera la tendencia a suplantar la realidad que significa. Pero no pueden alimentarse de la realidad representada cuando está separado de ella, se alimenta de otros signos para tomarlos y subordinarlos a sus fines. La vocación no escapa a este

Vocación universal suplantada por promoción de grupo de elegidos proceso. La vocación de Dios como llamada universal a la santidad y a la fraternidad ha querido ser suplantada, a través de las malas interpretaciones de elección, predestinación y vocación, por la promoción de un pequeño número de elegidos o la funcionarización de una casta que, intentando partir de su estatuto de signo, lo han elevado al rango de Dios. El proceso de Jesús alimentado por saduceos y fariseos es el testimonio de esa inversión perversa. Jesús es muerto por haber denunciado la falsa interpretación de elección de Israel. Volviendo a dar a la vocación de Dios su dimensión universal, Jesús ha destruido de una vez para siempre, como dice la carta a los Hebreos, la tentativa del signo que es la vocación del hombre queriendo igualarse con la de Dios (ver Flp 2,6). Fue preciso que Jesús derribara las mesas de los mercaderes del templo de Jerusalén y que el velo se desgarrara para que la llamada de Dios pudiese de nuevo hacerse entender por todos y que todos tuviesen la oportunidad de responder, sin enfeudar su historia a la de los funcionarios de la Ley y del Templo. La predicación de Jesús presentaba la vocación universal a la santidad, no la vocación que las autoridades religiosas habían acaparado para sí. Así cuanto más se había separado de esta vocación particular que se apoyaba en una elección captadora, más era impulsado a dirigirse a los niños, a las mujeres y a los hombres que ésta excluía de la vocación de Dios. Jesús enseñaba entonces que la vocación como respuesta del hombre a la lla- 
mada de Dios, es un signo-servidor. Es un servidor inútil, o sea, un Vocación signo que no debe subordinarse a otros signos, sino disponerlos al servicio de su maestro.

\section{Hacia nuevas vocaciones}

Si la Iglesia es servidora en cada uno de sus miembros, ninguno de ellos podrá poner a los otros a su servicio. La historia de la Iglesia está al servicio de la historia de todos los hombres que buscan cómo responder a la llamada de Dios. La vocación de la Iglesia es la de servir a Dios y a su Reino, no la de ser servida. Las funciones en la Iglesia son vocaciones para responder a la vocación de Dios, y no fines en sí mismos que es necesario hacer perdurar siempre y de la misma manera.

Para prevenirse de la idea de que la promoción de las vocaciones consiste en encontrar reclutas para puestos de poder en la Iglesia, vale la pena hacer mención de la distinción que Juan Pablo II hace en su exhortación postsinodal La Vida Consagrada, entre la misión eclesial de la vida consagrada en general y sus formas específicas, para aplicarla a las funciones en la Iglesia:

Las diferentes dificultades resultantes de la reducción del personal y de la disminución de las iniciativas, no deben en ninguna manera hacernos perder confianza en la fuerza evangélica de la vida consagrada, que estará siempre de actualidad y activa en la Iglesia. Si ninguno de los Institutos puede pretender la perennidad, la vida consagrada no contribuirá por ello menos a alimentar, entre los fieles, la respuesta de amor para con Dios y para con los hermanos. Por tanto, es preciso distinguir entre el destino histórico de un Instituto determinado o de una forma de vida consagrada y la misión eclesial de la vida consagrada como tal. La primera puede transformarse a causa de cambios debidos a las circunstancias, la segunda está llamada a perdurar"17.

Esta distinción se apoya en el hecho de que "la profesión de los consejos evangélicos pertenece indiscutiblemente a la vida y a la santidad de la Iglesia. Lo cual significa también que la vida consagrada, pre-

17 Juan Pablo II. La Vida Consagrada, Exhortación apostólica postsinodal, Ediciones Paulinas, Madrid 1996, pág. 110.

Funciones Iglesia $=$ vocaciones para responder a la vocación de Dios 
sente desde los orígenes, no podrá faltar jamás en la Iglesia, en tanto que elemento constituyente e irreemplazable que expresa la misma naturaleza de ella ${ }^{18}$. Este texto dice claramente que la vocación humana de los miembros de los Institutos de vida consagrada no es una lla-

Vocación vida consagrada: "historia de amor con el Señor" mada de Dios a desempeñar una función determinada en la Iglesia, sino que es una "historia de amor con el Señor"19, donde se articulan la respuesta cotidiana y el atractivo de la persona del Señor Jesús y la belleza del don total de sí por la causa del Evangelio. La función de signo de la vida consagrada es conservada a través de los modos cambiantes de su expresión concreta. Juan Pablo II pone en guardia contra una vocación religiosa concebida en términos de supervivencia de una forma particular de vida consagrada identificada con una función específica.

Si esto es así para la vocación religiosa, puede transferirse de la misma manera para toda vocación. La desaparición de una vocación particular no significa que la función de signo, o de respuesta a la llamada de Dios ha desaparecido, sino que "los cambios debidos a las circunstancias" exigen sin duda otras modalidades u otras formas de signo-servidor. La vocación universal de Dios podrá entonces expresarse en nuevas historias humanas, en nuevas vocaciones $y$, haciendo recordar los bienes futuros, las vocaciones de nuestros desiertos reproducirán la vida de la ciudad celeste. 